\title{
Effect of thawing methods on antioxidant capacity of frozen strawberry (Fragaria $x$ ananassa) and mulberry (Morusnigra)
}

\author{
Phuong H. Le, Minh N. Nguyen, \& Viet B. Nguyen* \\ Department of Chemical Engineering, Nong Lam University, Ho Chi Minh City, Vietnam
}

ARTICLE INFO
Research paper
Received: April 28, 2018
Revised: May 24, 2018
Accepted: June 02, 2018
Keywords
Antioxidant capacity
Freezing
Mulberries
Strawberries
Thawing
*Corresponding author
Nguyen Bao Viet
Email: nbviet@hcmuaf.edu.vn

Cited as: Le, P. H., Nguyen, M. N., \& Nguyen, V. B. (2018). Effect of thawing methods on antioxidant capacity of frozen strawberry (Fragaria $x$ ananassa) and mulberry (Morusnigra). The Journal of Agriculture and Development 17(3), 86-93.

\section{Introduction}

Recently, the consumption of fruits increased because of the expanding customer's knowledge about their benefits (Mohammad et al., 2004). Strawberries and mulberriesare not only favoured by the taste but also possess high content of ascorbic acid and bioactive phenolic compounds (Hartmann et al., 2008; Oszmiański et al., 2009; Bobinaite et al., 2012). Many studies have proven that phytochemical compounds of these berries exhibit antioxidant capacity, thus they have a role in prevention of many diseases such as carcinogenic, cardiovascular and otherchronic diseases (Hollman, 2001; Anttonen \& Karjalainen, 2005; Hartmann et al., 2008). Due tothe health promoting properties, these fruits are considered as natural functional products (Bobinaite et al., 2012).
In Vietnam, strawberries and mulberries are mostly grown at high land. Strawberries are harvested between December and April meanwhile harvesting time of mulberries is from February to March. Apart from being consumed fresh, they are also used in processed forms such as fruit juice, jam, concentrate or alcohol fermented juice. However, these berries are very perishable soft fruits and are harvested in season (Wills \& Kim, 1995). Consequently, freezing is one of the most common ways to prolong shelf life of these fresh fruits and supply the year-round raw materials for food industry (Mohammad et al., 2004; Bobinaite et al., 2012).

However, frozen fruits after thawing often face many quality problems due to the loss of firmness, drip loss and nutrition loss (Jeremiah, 1996; Hui, 2006). Freezing process often results in osmotic 
shrinkage and cell wall injuries which can lead to exposure of cellular compartments to oxidizing agents as oxygen, enzyme, light and heat (Hartmann et al., 2008; Oszmiański et al., 2009; Kruger et al., 2011). Industrial quick freezing can help to minimize damaged raw materials due to the formation of small ice crystals and less migration of water (Rhaman, 2007; Oszmiański et al., 2009). However, quick freezing does not always bring advantages, especially if thawing is not controlled carefully (Erickson \& Hung, 1997). In quick freezing, the water in food is not totally crystallized and easy to achieve the glass state which is convenient for food preservation at low temperature. But this means when thawing, a re-crystallization can happen and leads to the devitrification which can damage cell membranes (Lozano et al., 2000; Rhaman, 2007).

Besides freezing, thawing method is also very important to the quality of frozen fruit (Hui, 2006; Rhaman, 2007; Krüger et al., 2011). Especially in developing countries, at the small scale, most fruits are preserved in household freezers which only attain the minimum temperature of $-18^{\circ} \mathrm{C}$. In this case, thawing methods can contribute more to the physicochemical properties of final products. Normally, at low temperature, most chemical reactions are slowed down and this helps to limit the bio-chemical degradation of food, but during thawing some oxidative enzymes are re-activated at high concentration and promote these undesirable reactions (Jeremiah, 1996; Rhaman, 2007). Some studies showed that phenolic content and vitamin $\mathrm{C}$ are very unstable, thus they may be reduced in quantity under thawing conditions which leads to reduce antioxidant capacity and biological value (Garrote \& Bertone, 1989; Oszmiański et al., 2009; Syamaladevi et al., 2011). To link the effect of freezing or thawing on the nutritional values of food products, principal component analysis is a simple and useful tool which was successfully applied in many previous studies (Alvarez \& Canet, 2000; Soazo et al. 2013).

There were some studies about the effects of freezing and thawing on the quality of strawberries (Lindley, 1998; Holzwarth et al., 2012) but not much with mulberries. Moreover, understanding about the correlation between physicochemical properties of berry fruits after freezingthawing is limited. Therefore, the aim of this study was to investigate the effects of different thawing methods (thawing at ambient temperature, at low temperature and in a microwave) on the physicochemical properties of frozen Vietnamese strawberries and mulberries. Moreover, statistical tool was also applied to build the correlation between some parameters such as drip loss, thawing time with vitamin $\mathrm{C}$ content, total phenolic content and antioxidant capacity of these products.

\section{Materials and Methods}

\subsection{Chemicals}

Most chemicals used in this study included: 2,2'-aziro-bis-(3-ethylbenzo-thiazoline-6-sulfonic acid) diammonium salt (ABTS), 6-hydroxy2,5,7,8-tetramethylchroman-2-carboxylic acid (Trolox), FolinCiocalteu's phenol reagent, methanol (99.8\%), oxalic acid, acetic acid, xylem, formaldehyde acid, potassium persulphate ascorbic acid and gallic acid were purchased from Sigma-Aldrich. The distilled water was used in all experiments.

\subsection{Freezing and thawing samples}

Strawberry (Fragariaananasa) and mulberry (Morusnigra) fruits grown at Lam Dong highland (Lam Dong province, Vietnam) were harvested at commercial ripeness before being frozen at $18^{0} \mathrm{C}$ in a freezer (Sanaky, Japan) with a cooling rate of $1^{0} \mathrm{C} / \mathrm{min}$. After 1 week storage, fruits were thawed at cold temperature $\left(4-7^{0} \mathrm{C}\right)$ in a fridge, at ambient temperature and in a microwave oven (NN-SM330 MYUE, Panasonic, Japan) with the power of $184 \mathrm{~W}$ to reach to $+4^{0} \mathrm{C}$ at the core of fruits. The temperature was recorded by a digital thermometer (Barnant, USA). The thawing was stopped when the temperature of fruit reached the ambient temperature and thawing time was recorded for all samples.

\subsection{Drip loss and moisture determination}

Drip losses were determined by weighing immediately the exudates after thawing process completely using an analytical balance (TE214S, Sartorius, Germany). Moisture contents of fruits were determined by drying sample in a dryer (Memmert, Germany) at $105^{\circ} \mathrm{C}$ until the constant weight. The experiments were carried out in triplicate. 


\subsection{Vitamin $\mathrm{C}$ content}

Vitamin $\mathrm{C}$ content of thawed fruits was determined by using 2,6-dichlorophenol indophenols solution(ISO, 1984). Firstly, thawed samples were homogenized at speed of 8000 RPM during 20 minutes in a homogenizer (Ultra-Turrax T25, IKA, Germany) with oxalic acid (5\%, w/v for strawberry and $2 \%, \mathrm{w} / \mathrm{v}$ for mulberry) and centrifuged (EBA 20, Hettich, Germany) at 6000 RPM for 15 minutes. Next, the $5 \mathrm{ml}$ of supernatant was diluted with $5 \mathrm{ml}$ of buffer $\mathrm{pH} 4$ (potassium hydrogen phthalate solution), then added an excessive amount of 2,6-dichlorophenol indophenols and kept for 10 min. Finally, the solution was added with $10 \mathrm{ml}$ of xylen and then centrifuged again. The absorbance final supernatant was measured by using a UV-VIS spectrophotometer (Genesys 20, Thermo Scientific, USA) at wavelength $500 \mathrm{mn}$ to determine the remaining reagent. The amount of used reagent was the difference of the amount of reagent added and the amount of remaining reagent.

\subsection{Samples preparation for measurement of total phenolic content and antioxidant ca- pacity}

Similar to previous studies (Hartmann et al., 2008; Holzwarth et al., 2012), 1.5 gram of thawed fruits (including exudates) were extracted with $10 \mathrm{ml}$ of $80 \%$ methanol and $0.5 \mathrm{ml}$ of $\mathrm{HCl} 0.1 \mathrm{~N}$ for 5 minutes using a homogenizer (Ultra-Turrax T25, IKA, Germany) at $4^{0} \mathrm{C}$ in an ice bath. Next, the homogenate extract was centrifuged for 15 minutes at room temperature. Finally, the supernatant was transferred to a new tube and used for determining the antioxidant capacity and total polyphenols content.

\subsection{Total phenolic content}

Total polyphenol content was determined by using Folin-Ciocalteu reagent (FCR) (Singleton et al., 1999). A small amount of the extract (50 $\mu \mathrm{l}$ ) was mixed with $250 \mu \mathrm{l}$ of the FCR and 450 $\mu \mathrm{l}$ of distilled water and stand for $3 \mathrm{~min}$. Next, $2 \mathrm{ml}$ of a sodium carbonate $7.5 \%$ was added and mixed. The mixture was kept in dark for 2 hours at ambient temperature and then the absorbance was read at $765 \mathrm{~nm}$ using UV-VIS spectrophotometer (Genesys 20, ThermoScientific, USA). Total phenolic content was calculated from stan- dard curves of gallic acidand was expressed in mg of gallic acid equivalent per $100 \mathrm{~g}$ of fresh weight (mg GAE/100 g F.W).

\subsection{Antioxidant capacity}

Antioxidant capacity of thawed berries was done according to the method of Thaipong et al. (2006) with some modifications. Antioxidant capacity was evaluated by using Trolox Equivalent Antioxidant Capacity (TEAC) assay, based on ABTS radical scavenging capacity of the antioxidant molecules in berries extracts. When being reduced by the antioxidant molecules of sample, the dark green color of $\mathrm{ABTS}^{\bullet+}$ solution was decolorized. Briefly, ABTS ${ }^{\bullet}$ was prepared by mixing $7.4 \mathrm{mM}$ ABTS with $2.6 \mathrm{mM}$ potassium persulfate (ratio 1:1, v/v) in the dark at ambient temperature for 12 hours. Before measuring, ABTS $^{\bullet+}$ solution was diluted with methanol to an absorbance between 0.700 and 0.900 . This solution $(2850 \mu \mathrm{l})$ was mixed with $150 \mu \mathrm{l}$ of extract sample and kept in dark for 2 hours. The absorbance was read at $734 \mathrm{~nm}$ using spectrophotometer (Genesys 20, ThermoScientific, USA). The Trolox was used as a reference and the antioxidant capacity of berries extract was expressed in mmol/L trolox equivalent per $100 \mathrm{~g}$ of fresh weight (mMTE/100 g F.W).

\subsection{Statistical analysis}

All experiments were done in triplicates. Data were reported as the mean \pm confidence interval. Significant differences $(\alpha=0.05)$ among treatments were determined using one-way ANOVA and LSD test. The correlation between thawing methods and antioxidant capacity of samples was evaluated by PCA. SPSS software (version 16, IBM, USA) was used to run all statistical analysis.

\section{Results and Discussion}

\subsection{Thermal behavior of strawberry and mul- berry during thawing processes}

The temperature changes of berries during different thawing processes are presented in Figure 1. From the thermal curves, it was showed that thawing conditions had considerable effects on the thermal behavior of frozen fruit. With slow thawing as in fridge, the thermal behavior of 
these fruits had three stages including two sensible heating and one latent heating. The later stage did not appear when thawing at ambient temperature. Besides, the thawing time was also very different. At ambient temperature, the thawing time of strawberry and mulberry were 136 minutes and 113 minutes, respectively. These values reduced to 35 minutes (with strawberry) and 17 minutes (with mulberry) when thawing in fridge. When using microwave, the thawing time decreased dramatically to 2 minutes and 0.5 minutes for strawberry and mulberry, respectively. The difference of thawing time between two types of berries mainly depends on the size of fruits. With smaller size, mulberry required less energy than strawberry when thawing in same condition. Consequently, the thawing time of mulberry was shorter than that of strawberry.

According to the Figure 1, it was clearly showed the effects of freezing on the thermal behavior of both types of berry during thawing. With slow cooling rate (approximately $1^{\circ} \mathrm{C} / \mathrm{min}$ ), water in fruits was maximum crystallized before reaching the glass state at $-18^{\circ} \mathrm{C}$. This helped prevent the re-crystallization of water in fruits which could appear when thawing at slow rate. Thus, the temperature change of frozen fruits during cool thawing was stable and there were no signs of exothermic on thawing curves at this condition. This means that the tissue in fruits can be better protected from the devitrification.

Effect of thawing methods on drip loss of frozen fruit is presented Table 1 comparing the drip loss of strawberry and mulberry when thawing in a microwave oven, at ambient and cold temperature. It can be clearly seen that berries thawed in a microwave oven had the least drip loss. In comparison with strawberry, mulberry had a great amount of drip loss after thawing due to the difference in water content of fruits. Water content of mulberry was higher than that of strawberry $(94.85 \pm 2.60 \%$ comparing to $89.11 \pm 2.53 \%)$, thus mulberry may contain more free water. The high amount of bound water in strawberry can lead to difficulties in freezing this fruit, thus drip loss was less after thawing. For both of berries, thawing in cold temperature (the longest thawing time) had the highest drip loss. This result was probably the consequences of dehydration when thawing. The slow freezing velocity led to the formation of large ice crystals in the extracellular space of fruits which causes tearing of cell walls, dislocation of cell contentsafter thawing (Lindley, 1998; Delgado \& Rubiolo, 2005; Holzwarth, 2012). This makes cell contents lose their waterholding capacity, thus they cannot hold their existing water inside the cells and leakage normally occurs (Müftügil \& Yigit, 1986). Consequently, when frozen fruits were thawed at slow velocity, water was lost gradually. However, if the thawing rate is higher, cells recover structure and perhaps absorb a part of water due to the reverse osmosis. Briefly, the longer thawing process results in the more drip loss.

Table 1. Drip loss (\%) of Strawberry and mulberry at different thawing methods ${ }^{1}$

\begin{tabular}{ccc}
\hline Thawing methods & Strawberry & Mulberry \\
\hline Microwave & $1.25 \pm 0.11^{\mathrm{a}}$ & $3.94 \pm 0.49^{\mathrm{c}}$ \\
Ambient & $1.82 \pm 0.30^{\mathrm{a}}$ & $15.95 \pm 0.46^{\mathrm{d}}$ \\
temperature & $2.55 \pm 0.05^{\mathrm{b}}$ & $17.75 \pm 1.82^{\mathrm{d}}$ \\
\hline
\end{tabular}

${ }^{1}$ Results are expressed as mean of three replicate measurements \pm standard deviation. Values followed with different superscript (vertical) were significant different $(P<0.05)$.

\subsection{Effect of thawing method on remaining vi- tamin $\mathrm{C}$, total phenolic content and an- tioxidant capacity}

The effect of thawing methods on vitamin $\mathrm{C}$ and phenolic contents of both of berries are presented in Table 2. ANOVA and LSD tests showed that thawing methods affected significantly these compounds. Both types of fruit thawed in microwave remained the highest vitamin content $(24.43 \mathrm{mg} / 100 \mathrm{~g} \mathrm{~F} . \mathrm{W}$ for strawberry and 16.60 $\mathrm{mg} / 100 \mathrm{~g}$ F.W for mulberry) whereas thawing in fridge resulted in the highest loss. This result agreed with that of Holzwarth et al. (2012) who reported that thawing of block frozen strawberry at $4^{0} \mathrm{C}$ for 24 hours caused the highest loss of vitamin C $(34.8 \%)$ while thawing in microwave oven attributed only $4 \%$ of vitamin C loss. Similarly, thawing methods affected the same tendency loss on total polyphenol content of mulberry as vitamin C losses, whereas regarding strawberry, thawing at ambient temperature caused the highest loss as coup and with thawing at cold temperature (Table 2).

After thawing, the content of phenolic compounds remaining in strawberry ranged from 227 to $331 \mathrm{mg}$ GAE/100 g F.W. Li et al. (2003) reported that total polyphenol contents in 6 strawberry varieties grown in China stored at differ- 


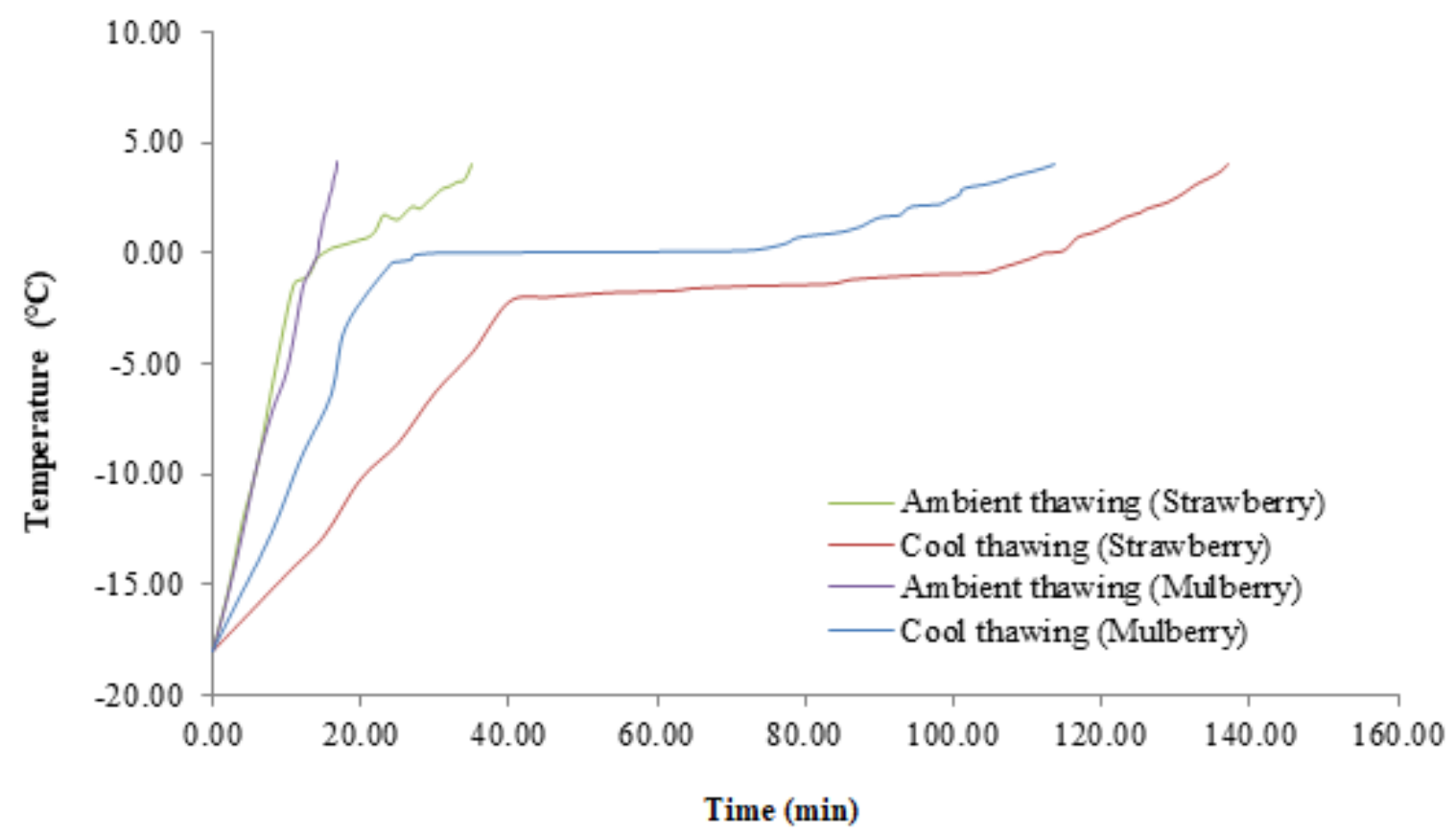

Figure 1. Thawing curves of strawberry and mulberry at different conditions (ambient thawing and cool thawing).

ent temperature and duration time were between 197-377 mg GAE/g F.W. However, the value in current studywas less than 2-5 times in comparison to that of 5 varieties grown at Korea, which ranged from 959 to $2500 \mathrm{mg}$ GAE/100 g F.W (Bae \& Suh, 2007). Variation in content of total polyphenol was that Bae et al. (2007) analysed in fresh strawberry while our study evaluated total phenolic content of thawed berries which were surely lost during thawing. Moreover, not only cultivars but also maturity, size and analyzing procedure could be factors contributing to the difference of these compounds(Olsson et al., 2004; Scalo et al., 2005; Bobinaitè et al., 2012).

There was a significant difference among the thawing methods for the antioxidant capacity of strawberry and mulberry (Table 3). In comparison with mulberry, strawberry had higher vitamin $\mathrm{C}$ and polyphenol contents, thus the antioxidant capacity of this fruit was also much higher. The lowest antioxidant capacity was found in berries thawed at cold temperature (0.88 mMTE/100 g F.W for strawberry and 1.59 mMTE/100 g F.W for mulberry). Microwave oven was also proved to be the best method to thaw frozen strawberry but not to mulberry. Sur- prisingly, the antioxidant capacity of mulberry thawed in microwave oven (2.90 mMTE/100 gF.W) was lower than that thawed at ambient temperature (3.22 mMTE/100 g F.W), although thawing time in the oven was only 30 seconds. Presumably, mulberry is very soft texture and small size, with the diameter about $0.8 \mathrm{~cm}$. Thus, the degradation of antioxidant capacity was affected by heating of microwave oven.

\subsection{Relation between physical and chemical properties of thawed strawberry and mul- berry}

The Principle Component Analysis (Figure 2) showed the correlation between drip loss, thawing time with vitamin $\mathrm{C}$ content, total phenolic content and antioxidant capacity of thawed fruit. Firstly, if the amount of drip loss was higher, the less vitamin $\mathrm{C}$ remained in thawed berries. This can be explained based on the high solubility of this vitamin in water. Therefore, microwave thawed fruits which have low drip loss often have a high retention fo vitamin $\mathrm{C}$ content. Secondly, thawing time seems to have considerable negative effect on total phenolic content and antioxidant capacity of thawed fruit. This result 
Table 2. Vitamin $\mathrm{C}$ and total phenolic contents in thawed strawberry and mulberry

\begin{tabular}{cccc}
\hline Fruit & Thawing methods & Vitamin C $(\mathrm{mg} / 100 \mathrm{gF} . \mathrm{W})$ & TPC $(\mathrm{mgGAE} / 100 \mathrm{gF} . \mathrm{W})$ \\
\hline \multirow{3}{*}{ Strawberry } & Microwave & $24.43 \pm 0.46^{\mathrm{a}}$ & $331.02 \pm 1.11^{\mathrm{c}}$ \\
& Ambient temperature & $22.26 \pm 0.38^{\mathrm{b}}$ & $227.66 \pm 3.71^{\mathrm{d}}$ \\
& Cold temperature & $21.00 \pm 0.48^{\mathrm{b}}$ & $277.56 \pm 20.90^{\mathrm{e}}$ \\
\hline \multirow{3}{*}{ Mulberry } & Microwave & $16.60 \pm 0.24^{\mathrm{f}}$ & $443.37 \pm 37.47^{\mathrm{h}}$ \\
& Ambient temperature & $14.79 \pm 0.88^{\mathrm{f}}$ & $377.16 \pm 22.03^{\mathrm{i}}$ \\
& Cold temperature & $9.25 \pm 1.05^{\mathrm{g}}$ & $278.49 \pm 13.92^{\mathrm{j}}$ \\
\hline
\end{tabular}

${ }^{\mathrm{a}-\mathrm{j}}$ Results are expressed as mean of three replicate measurements \pm standard deviation. Values followed with different superscript (vertical) were significant different $(P<0.05)$.

Table 3. Antioxidant capacity of thawed strawberry and mulberry by TEAC assay (mMTE/100 gF.W)

\begin{tabular}{ccc}
\hline Thawing methods & Strawberry & Mulberry \\
\hline Microwave & $1.31 \pm 0.01^{\mathrm{a}}$ & $2.90 \pm 0.10^{\mathrm{d}}$ \\
Ambient temperature & $0.98 \pm 0.01^{\mathrm{b}}$ & $3.22 \pm 0.03^{\mathrm{e}}$ \\
Cold temperature & $0.88 \pm 0.01^{\mathrm{c}}$ & $1.59 \pm 0.16^{\mathrm{f}}$ \\
\hline
\end{tabular}

$\overline{\mathrm{a}-\mathrm{f}}$ Results are expressed as mean of three replicate measurements \pm standard deviation. Values followed with different superscript (vertical) were significant different $(P<0.05)$.

\section{Component Plot in Rotated Space}

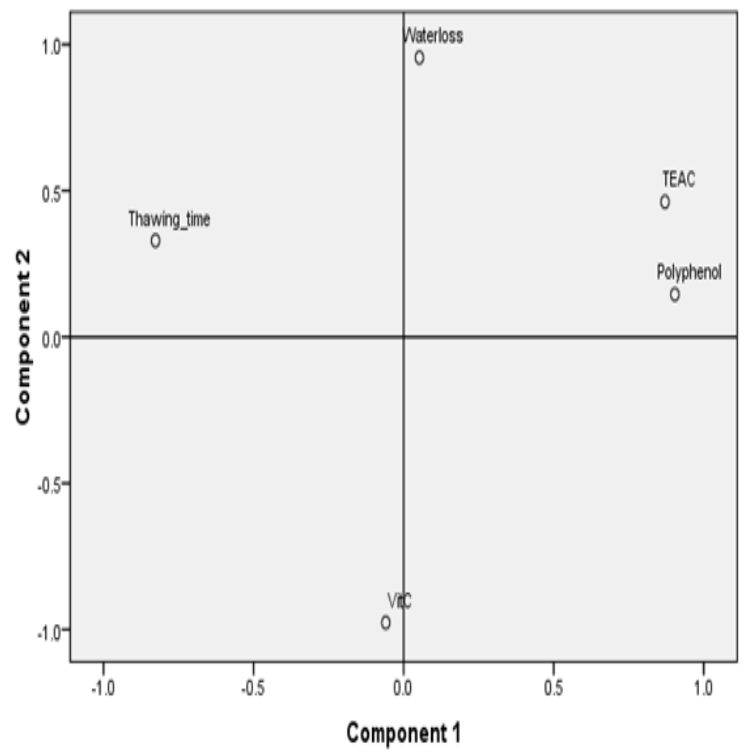

Figure 2. Principle Component Analysis of physical and chemical properties of frozen fruits after thawing.

is consistent with Oszmiański et al.(2009) who claimed that thawing frozen strawberry in microwave oven (the shortest thawing time) retaining more phenolic content than thawing at $20^{\circ} \mathrm{C}$ for 20 hours. It is assumed that the degradation of anthocyanin by the activities of polyphenol oxidase (PPO) and peroxidase (POD) which is still active at low temperature during long thawing process (Cano et al., 1995; Chisari et al., 2007; Oszmiański et al., 2009). On the other hands, the exposure to oxygen during thawing can attribute to oxidation of phytochemical compounds. Consequently, faster thawing method in microwave oven is better to achieve high content of phenolic compounds in frozen berries (Oszmiański et al., 2009).

\section{Conclusions}

The study revealed that the microwave oven was the best method for thawing frozen strawberry and mulberry. Interestingly, berry fruits thawed at cold temperature $\left(4^{0} \mathrm{C}\right)$ increased drip loss and decreased vitamin $\mathrm{C}$, polyphenol contents, thus reducing antioxidant capacity of berries. It was assumed that prolonged thawing process increased the exposure time of vitamin $\mathrm{C}$ and polyphenol compounds to oxygen and enzyme degradation. Furthermore, PCA showed that the retention of vitamin $\mathrm{C}$ was correlated to drip loss, whereas phenolic content and antioxidant capacity in thawed berries depended on thawing time. Thus, thawing regime is the important factor to assure quality of frozen strawberry and mulberry after thawing. 


\section{References}

Alvarez M. D., \& Canet W. (2000). Principal com- ponent analysis to study the effect of temperature fluctuations during storage of frozen potato. European Food Research and Technology 211(6), 415-421.

Anttonen, M. J., \& Karjalainen, R. O. (2005). Environmental and genetic variation of phenolic compounds in red raspberry. Journal of Food Composition and Analysis 18(8), 759-769.

Anttonen, M. J., Hoppula, I., Nestby, R., Verheul, M. J., \& Karjalainen, R. O. (2006). Influence of fertilization, mulch color, early forcing, fruit order, planting date, shading, growing environment, \& genotype on the contents of selected phenolics in strawberry (Fragaria $x$ ananassa Duch.) fruits. Journal of Agriculture and Food Chemistry 54(7), 2614-2620.

Bae, S. H., \& Suh, H. J. (2007). Antioxidant acticities of five different mulberry cultivars in Korea. Journal of Food Science and Technology 40(6), 955-962.

Bobinaitè, R., Viškelis, P., \& Venskutonis, P. R. (2012). Variation of total phenolics, anthocyanins, ellagic acid and radical scavenging capacity in various raspberry (Rubus spp.) cultivars. Food Chemistry 132(3), 14951501 .

Cano, M. P., de Ancos, B., \& Lobo, G. (1995). Peroxidase and polyphenoloxidase acitivities in papayas during postharvest ripening and after freezing/thawing. Journal of Food Science 60(4), 815-817.

Chisari, M., Barbagallo, R. N., \& Spagna G. (2007). Characterisation of polyphenol oxidase and peroxidase and influence on browning of cold stored strawberry fruit. Journal of Agriculture and Food Chemistry 55(9), 3469-3476.

Delgado, A. E., \& Rubiolo, A. C. (2005). Microstructural changes in strawberry after freezing and thawing processes. Journal of Food Science and Technology 38(2), 135-142.

Erickson, M. C., \& Hung Y. C. (1997). Quality in Frozen Food. New York, USA: Springer.

Garrote, R. L., \& Bertone, R. A. (1989). Osmotic concentration at low temperature of frozen strawberry halves. Effect of glycerol, glucose and sucrose solutions on exudates loss during thawing. Journal of Food Science and Technology 22(5), 264-267.

Hartmann A., Patz C. D., Andlauer W., Dietrich H., \& Ludwig M. (2008). Influence of processing on quality parameters of strawberries. Journal of Agriculture and Food Chemistry 56(20), 9484-9489.

Hollman, P. C. H. (2001). Evidence for health benefits of plant phenols: local or systemic effects. Journal of the Science of Food and Agriculture 81(9), 842-852.

Holzwarth, M., Korhummel S., Carle R., \& Kammerer, D. R. (2012). Evaluation of the effects of different freezing and thawing methods on color, polyphenol and ascorbic acid retention in strawberries (Fragaria $x$ ananassa Duch.). Food Research International 48(1), 241-248.
Hui, Y. H. (2006). Handbook of fruits and fruit processing. New Jersey, USA: Blackwell Publishing.

ISO (International Organization for Standardization). (1984). Fruit and vegetable products - acid ascorbic determination. ISO, 6557-6562.

Jeremiah, L. E. (1996). Freezing effects on food quality. New York, USA: Marcel Dekker.

Krüger, E., Dietrich, H., Schöpplein, E., Rasim, S., \& Kürbel, P. (2011). Cultivar, storage conditions and ripening effects on physical and chemical qualities of red raspberry fruit. Postharvest Biology and Technology 60(1), 31-37.

Li, C., Huang, W. Y., Wang, X. N., \& Liu, W. X. (2013). Oxygen radical absorbance capacity of different varieties of strawberry and the antioxidant stability in storage. Molecules 18(2), 1528-1539.

Lindley, M. G. (1998). The impact of food processing on antioxidants in vegetable oils, fruits and vegetables. Trends Food Science and Technology 9(8-9), 336-341.

Lozano, J. E., Anon, C., Arias, E. P., \& Canovas, G. V. B. (2000). Trends in Food Engineering. New York, USA: CRC Press.

Müftügil, N., \& Yigit, V. (1986). Thawing of frozen strawberries. International Journal of Refrigeration 9, 3133 .

Mohammad, A. S., Mohsen, B. F., \& Zohreh, H. E. (2004). Effect of low temperature on the ascorbic acid content and quality characteristics of frozen strawberry. Food Chemistry 86(3), 357-363.

Olsson, M. E., Ekvall, J., Gustavsson, K. E., Nilsson, J., \& Pillai, D. (2004). Antioxidants, low molecular weight carbohydrates, and total antioxidant capacity in strawberries (Fragaria $x$ ananassa): Effects of cultivar, ripening, and storage. Journal of Agriculture and Food Chemistry 52(9), 2490-2498.

Oszmiański, J., Wojdylo, A., \& Kolniak, J. (2009). Effect of L-ascorbic acid, sugar, pectin and freeze-thaw treatment on polyphenol content of frozen strawberries. Food Science and Technology 42(2), 581-586.

Rhaman, M. S. (2007). Handbook of food preservation ( $2^{\text {nd }}$ ed.). New York, USA: CRC Press.

Scalzo, J., Politi, A., Pellegrini, N., Mezzetti, B., \& Battino, M. (2005). Plant genotype affects total antioxidant capacity and phenolic contents in fruit. Nutrition 21(2), 207-213.

Singleton, V. L., Orthofer, R., \& Raventos, R. M. L. (1999). Analysis of total phenolic and other oxidation substrates and antioxidants by means of folinciocalteu reagent. Methods in Enzymology 299, 152-178.

Soazo M., Perez L. M., Rubiolo A. C., \& Verdini R. A. (2013). Effect of freezing on physical properties of whey protein emulsion films. Food hydrocolloids 1(2), 256263. 
Syamaladevi, R. M., Sablani, S. S., Tang, J., Powers, J., \& Swanson, B. G. (2011). Stability of anthocyanins in frozen and freeze-dried raspberries during long term storage: in relation to glass transition. Journal of Food Sciences 76(6), 414-421.

Thaipong, K., Boonprakob, U., Crosby, K., Zevallos, L. C., \& Byrne, D. H. (2006). Comparison of ABTS, DPPH, FRAP, and ORAC assays for estimating antioxidant activity from guava fruit extracts. Journal of Food Composition and Analysis 19(6-7), 669-675.

van Buggenhout, S., Sila, D. N., Duvetter, T., van Loey, A., \& Hendrickx, M. (2009). Pectins in processed fruits and vegetables: Part III - Texture engineering. Comprehensive Reviews in Food Science and Food Safety 8(2), 105-117.
Wicklund, T., Rosenfeld, H. J., Martinsen, B. K., Sundfør, M. W., \& Lea, P. (2005). Antioxidant capacity and color of strawberry jam as influenced by cultivar and storage conditions. Food Science and Technology 38(4), 387-391.

Wills R. B. H., \& Kim G. H. (1995). Effect of ethylene on postharvest life of strawberries. Postharvest Biology and Technology 6(3-4), 249-255. 